\title{
Erratum zu: Pkw-Klimatisierung
}

\section{Erratum zu: \\ H. Großmann und C. Böttcher, Pkw-Klimatisierung, VDI-Buch, https://doi.org/10.1007/978-3-662-59616-6}

Die Originalfassung des Buches wurde versehentlich veröffentlicht ohne alle Korrekturen der Autoren einzubinden. Das Buch wurde nun korrigiert. Die Links zu den korrigierten Kapiteln finden Sie untenstehend:

Die aktualisierten Versionen der Kapitel finden Sie unter https://doi.org/10.1007/978-3-662-59616-6_1 https://doi.org/10.1007/978-3-662-59616-6_2 https://doi.org/10.1007/978-3-662-59616-6_3 https://doi.org/10.1007/978-3-662-59616-6_4 https://doi.org/10.1007/978-3-662-59616-6_5 https://doi.org/10.1007/978-3-662-59616-6_6 https://doi.org/10.1007/978-3-662-59616-6_8 https://doi.org/10.1007/978-3-662-59616-6_10 https://doi.org/10.1007/978-3-662-59616-6_11 https://doi.org/10.1007/978-3-662-59616-6_13 https://doi.org/10.1007/978-3-662-59616-6_14 https://doi.org/10.1007/978-3-662-59616-6 